\title{
ANALISIS DAN PERANCANGAN ENTERPRISE ARCHITECTURE DIREKTORAT METROLOGI PADA FUNGSI LAYANAN PELANGGAN DAN PENGAWASAN MENGGUNAKAN FRAMEWORK TOGAF ADM
}

\author{
${ }^{1}$ Ana Meilani Puspitasari, ${ }^{2}$ Rachmadita Andreswari, ${ }^{3}$ Ridha Hanafi \\ 1,2,3 Program Studi Sistem Informasi, Fakultas Rekayasa Industri, Telkom University \\ 1'meilani.ana@gmail.com, ${ }^{2}$ andreswari@gmail.com, ${ }^{3}$ ridhanafi@gmail.com
}

\begin{abstract}
Abstrak - Direktorat Metrologi merupakan dinas tingkat eselon II yang berada dibawah kementerian perdagangan. Direktorat Metrologi mempunyai tugas dalam pengelolaan bidang metrologi legal. Dalam melaksanakan tugasnya, Direktorat Metrologi menjalankan berbagai proses bisnis baik proses bisnis utama maupun pendukung. Kompleksitas proses bisnis yang dijalankan menjadi alasan dibutuhkannya teknologi informasi sebagai penunjang. Namun kebutuhan bisnis harus selaras dengan teknologi informasi yang digunakan. Enterprise architecture merupakan metode yang digunakan untuk menyelaraskan antara bisnis dengan teknologi informasi. TOGAF ADM digunakan sebagai pedoman dalam penyusunan enterprise architecture. Domain pada TOGAF ADM yaitu business architecture, data architecture, application architecture, dan technology architecture. Penyusunan enterprise architecture berdasarkan aturan hukum yang berlaku, visi misi Direktorat Metrologi, dan rencana strategis yang dibuat oleh kementerian perdagangan. Perancangan dilakukan pada fungsi bisnis layanan pelanggan dan pengawasan Direktorat Metrologi. Dari perencanan enterprise architecture diperoleh pedoman atau gambaran teknlogi informasi yang akan diimplementasikan sesuai kebutuhan bisnis dalam upaya mencapai tujuan strategis.
\end{abstract}

Kata kunci: Direktorat Metrologi, Enterprise Architecture, TOGAF ADM, Layanan Pelanggan, Pengawasan

\section{PENDAHULUAN}

Saat ini, perkembangan teknologi semakin pesat. Pemanfaatan teknologi informasi (TI) telah digunakan oleh berberbagai pihak. Perkembangan teknologi tersebut dan banyaknya manfaat yang dapat diperoleh dengan pemanfaatan TI membuat banyak organisasi beralih menggunakan TI dalam menjalankan proses bisnisnya maupun dalam pengelolaan aliran informasi. Salah satu faktor pendorong pemanfaatan sistem informasi dalam organisasi adalah semakin meningkatnya kebutuhan dalam fungsi bisnis yang dijalankan [1].

Pemanfaatan TI juga sudah dilakukan oleh Direktorat Metrologi. Pemanfaatan tersebut dilakukan dalam bentuk penggunaan aplikasi dalam membantu menjalankan proses bisnisnya. Namun pemanfaatan teknologi informasi yang ada saat ini belum maksimal. Hal ini dapat dilihat dari sistem informasi yang digunakan saat ini belum bisa memenuhi kebutuhan bisnis secara keseluruhan. Pada fungsi layanan pelanggan penggunaan teknologi bersifat partial, pelayanan online hanya bisa dilakukan untuk permohonan perizinan. Pelayanan permohonan pengujian hanya bisa dilakukan di loket. Dan sistem informasi yang ada belum mampu memenuhi kebutuhan informasi untuk fungsi bisnis lain. Bahkan pada fungsi pengawasan belum ada sistem informasi yang menujang jalannya proses bisnis yang dilakukan.

Salah satu penyebab kurang maksimalnya penggunaan TI adalah kurangnya perencanaan dan tanpa memikirkan kunci utama dalam proses pengembangan sistem informasi yaitu perancangan, perancangan sistem informasi yang baik harus melihat dari berbagai sudut pandang pengembangan sistem, dimulai dari mendefinisikan arsitektur bisnis yang ada dalam organisasi, mendefinisikan arsitektur data yang akan digunakan, mendefinisikan arsitektur aplikasi yang akan dibangun serta mendefinisikan arsitektur teknologi yang mendukung jalannya sistem informasi tersebut [1].

Berdasarkan kondisi diatas perlu adanya pedoman dalam pengembangan teknologi informasi. Enterprise architecture memberikan definisi dan pandangan secara high level tentang bisnis proses dan sistem informasi dari suatau perusahaan. Tujuan utama EA adalah menentukan keadaan bisnis proses dan sistem informasi masa depannya dan menyediakan roadmap untuk implementasi keadaan saat ini ke keadaan target [2]. Tata kelola organisasi dapat menentukan perubahan yang perlu dilakukan dalam kondisi saat ini dengan kondisi yang diinginkan nanti [3]. Dengan adanya Enterprise Architecture (EA) maka akan memberikan penjelasan dan dokumentasi saat ini dan yang diinginkan antara bisnis dan teknologi informasi, di dalamnya akan menggambarkan arsitektur baseline dan arsitektur target sehingga akan tercipta keselarasan antara strategi bisnis dan TI [4]. Pada perancangan enterprise architecture yang dilakukan oleh Siti Zulaiha [5] pada Direktorat Jenderal Perbendaharaan Departemen Keuangan, EA digunakan sebagai rekomendasi untuk menanggapi perubahan struktur organisasi sehingga mempengaruhi struktur pengambulan keputusan. Perancangan dilakukan berdasarkan proses bisnis yang dijalankan organisasi. Sedangkan penelitian yang dilakukan Adityo Affandi [6] Perancangan enterprise architecture dilakukan dengan pembuatan sistem informasi untuk pelayanan pelanggan PDAM Kota Cirebon. Pembuatan sistem informasi tersebut dikarenakan pentingnya menjaga kualitas pelayanan terhadap 
pelanggan. Enterprise architecture dipilih karena dibutuhkan blueprint dalam proses pembangunan dan pengembangan sistem informasi pelayanan pelanggan PDAM Kota Cirebon. Enterprise Architecture Planning digunakan sebagai acuan dalam proses perancangan. Sistem yang dibangun merupakan pengembangan sistem yang sudah ada. Pengembangan dilakukan dengan penambahan aplikasi dan pengembangan aplikasi yang sudah ada. Selain itu pengembangan dapat dilakukan dengan pembuatan model CRM seperti yang dilakukan Imam Ghozali [7] dengan membuat model CRM pada E-Government di Dinas Kelautan dan Perikanan DIY. CRM dibuat sebagai akselerator pembangunan wilayah DIY. CRM dibuat dengan identifikasi data berdasarkan bisnis yang dijalankan. Selanjutnya dipetakan ke dalam kandidat aplikasi yang akan dibangun.

Dalam perancangan enterprise architecture diperlukan framework sebagai metode implementasi EA. Berbagai macam framework yang dapat digunakan untuk menyusun enterprise architecture seperti, EAP, FEAF, DoDAF, Zachman, TOGAF, TEAF. TOGAF dipilih sebagai framework dalam penyusunan EA karena TOGAF memiliki karakteristik yang sesuai dengan masalah yang ada di Direktorat Metrologi. Karakteristik TOGAF yaitu open source, focus pada siklus implementasi (ADM), pendekatannya bersifat menyeluruh, memiliki alat bantu (tools) untuk perencanaan dan proses yang lengkap [8]. TOGAF memandang implementasi EA sebagai proses yang berkesinambungan, sehingga lebih fokus pada continuum dan repository [9].

Rancangan enterprise architecture diperlukan untuk mengatasi permasalahan yang ada, yaitu tidak adanya baseline architecture yang menyebabkan pengembangan TI tidak terarah sehingga pemanfaatan teknologi informasi tidak maksimal. Pemanfaatan teknologi informasi berupa sistem informasi yang ada saat ini tidak dapat memenuhi kebutuhan bisnis Direktorat Metrologi dalam mencapai tujuan organisasi.

\section{STUDI LITERATUR}

\section{A. Enterprise architecture}

Enterprise architecture merupakan pendekatan untuk mengelola komplekitas struktur organisasi, teknologi informasi, dan lingkungan bisnis, dan memfasilitasi integrasi antara strategi, pegawai, bisnis, dan teknologi informasi untuk mencapai tujuan [10]. Enterprise architecture memiliki tujuan untuk mengoptimalka proses yang ada, baik yang masih manual maupun sudah terotomasi ke lingkungan yang terintegrasi sehingga tanggap dalam menghadapi perubahan yang terjadi. EA membantu dalam menyelaraskan antara strategi bisnis dan teknologi informasi. Hasil akhirnya, EA akan membuat business operation dan IT operation lebih efektif.

\section{B. TOGAF ADM}

ADM merupakan metode lojik dari TOGAF yang digunakan untuk pengembangan dan pemeliharaan arsitektur organisasi. Metode yang ada pada ADM membentuk siklus yang iterative dan berulang untuk keseluruhan proses, antar fase, dan setiap fase. ADM merupakan metode umum sehingga dalam praktiknya dapat disesuaikan dengan kebutuhan organisasi [11]. Fase-fase pada ADM saling berurutan dan berhubungan satu sama lain. Berikut adalah fase-fase pada ADM [12]:

1. Preliminary Phase

Tahap persiapan dalam pengembangan arsitektur perusahaan dengan mendefinisikan framework dan menentukan prisnipprinsip arsitektur sebagai dasar dalam perancangan arsitektur.

2. Phase A : Architecture Vision

Merupakan tahap awal dalam proses pengembangan arsitektur dengan mendefinisikan ruang lingkup pengembangan, identifikasi stakeholder, seta meminta dan memperoleh persetujuan. Selain itu digambarkan secara high level dari solusi yang akan diusulkan.

3. Phase B : Business Architecture

Menggambarkan pengembangan arsitektur bisnis yang meliputi, proses bisnis, fungsi organisasi, dan layanan bisnis untuk mendukung visi arsitektur (architecture vision) yang telah disetujui.

4. Phase C : Information System Architecture

Menggambarkan arsitektur sistem informasi yang mencakup arsitektur data dan arsitektur aplikasi untuk mendukung visi arsitektur (architecture vision).

5. Phase D : Technology Architecture

Menggambarkan pengembangan arstektur teknologi berupa logical dan physical application untuk mendukung visi arsitektur (architecture vision).

6. Phase E : Opportunities and Solution

Perencanaan implementasi awal dengan mengidentifikasi proyek apa yang diperlukan untuk mencapai arsitektur yang telah didefinisikan sebelumnya.

\section{Phase F : Migration Planning}

Mengidentifikasi manfaat, biaya, dan ketergantungan proyek yang akan dilakukan dalam proses migrasi. Daftar prioritas proyek akan menjadi dasar unuk membuat perencanaan yang detail dalam proses migrasi ke arsitektur target.

8. Phase G : Implementation Governance

Memberikan pengawasan kesesuaian antara arsitektur target dengan implementasi arsitektur.

\section{Phase H : Architecture Change Management}

Menetapkan prosedur dalam mengelola perubahan pada arsitektur yang baru.

10. Requirements Managements

Proses mengelola kebutuhan pada seluruh fase ADM dan sesuai dengan keutuhan bisnis.

\section{METODOLOGI PENELITIAN}

Model konseptual merupakan sebuah kerangka kerja yang mengambarkan abstraksi dari kenyataan model yang akan dibuat. Selain itu menjelaskan hubungan antara objective, input, dan output dari model yang akan dibuat [13]. Gambar 1 menggambarkan hubungan variable yang digunakan dalam penelitian. Model konseptual membahas kebutuhan atau masalah yang menjadi dasar adanya penelitian, knowledge base 
yaitu ilmu pengetahuan yang digunakan sebagai dasar dalam melakukan penelitian dan artifacts hasil dari penelitian.

Pada bagian kebutuhan terdapat masalah utama yang melatarbelakangi penelitian, yaitu penggunaan sistem belum mencakup keseluruhan proses bisnis serta sistem yang ada pada saat ini belum terintegrasi sehingga belum bisa memenuhi kebutuhan bisnis. Terdapat penjelasan mengenai studi kasus yang diangkat dalam penelitian. Selain itu terdapat lingkungan yang mempengaruhi dalam penelitan yang terdiri dari orang menjadi objek dalam penelitian, visi misi, rencana srategis, dan aturan yang ada dalam organisasi, dan yang terakhir adalah teknologi yang digunakan pada organisasi. Pada knowledge base digunakan konsep enterprise architecture sebagai pendekatan dalam pemecahan masalah, khususnya dengan framework TOGAF ADM. Metode yang digunakan dalam penelitian yaitu wawancara, observasi, studi literature, dan merujuk pada arsitektur referensi terkait. Artifact yang dihasilkan berupa catalog, diagram, dan matriks yang menggambarkan rancangan enterprise architecture yang telah dibuat. Evaluasi dilakukan dengan melakukan analisis dari pihak organisasi apakah rancangan telah sesuai untuk memenuhi kebutuhan organisasi.

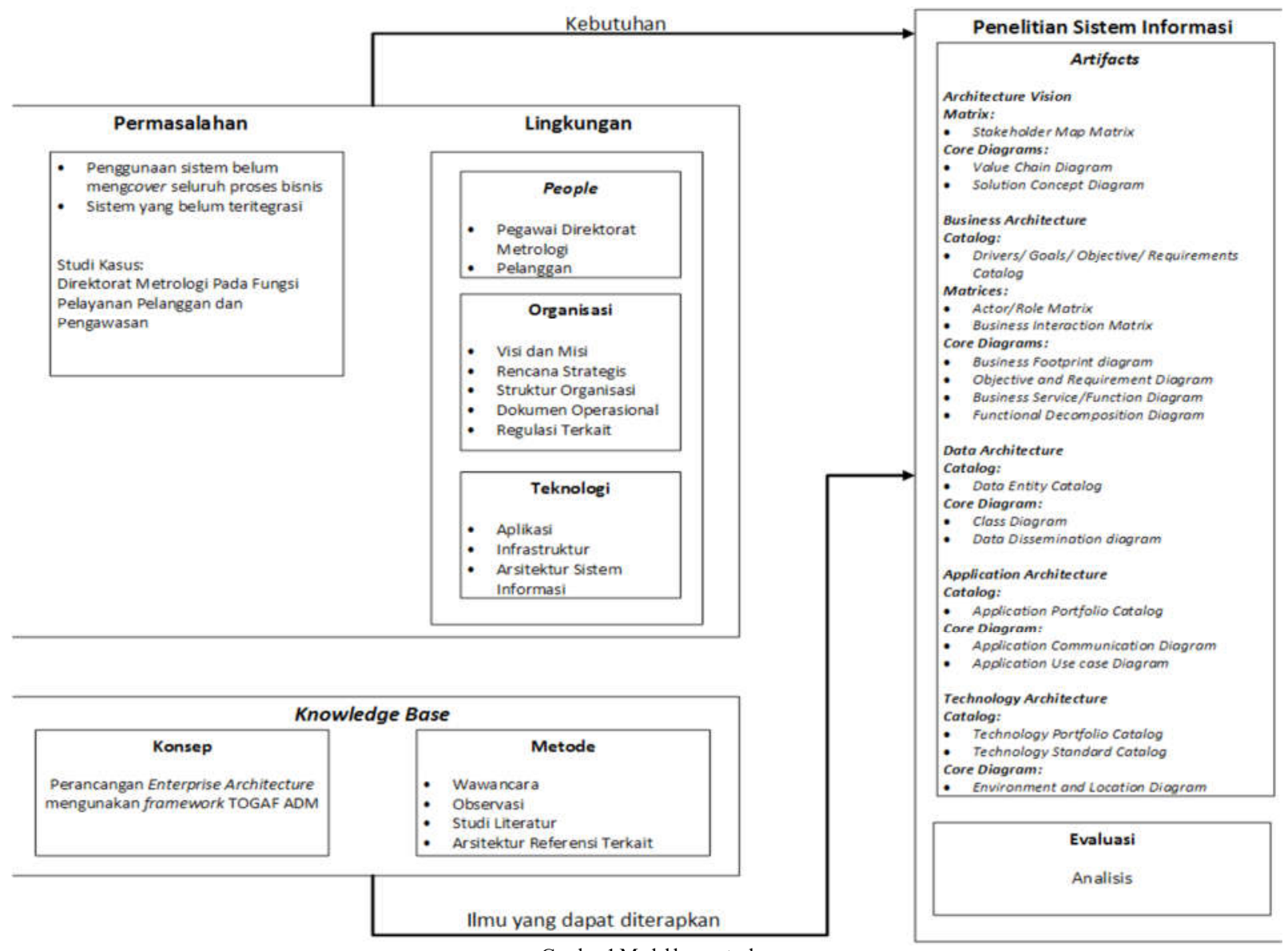

Gambar 1 Model konseptual

IV. HASIL DAN ANALISIS

\section{A. Preliminary phase}

Fase preliminary merupakan tahap persiapan dalam framework TOGAF ADM. Fase ini dilakukan persiapan dalam perancangan enterprise architecture. Pada tahap ini didefinisikan prinsip-prinsip arsitektur bisnis, data, aplikasi dan teknologi yang digunakan sebagai acuan dalam merancangan enterprise architecture Direktorat Metrologi. Tabel II menjelaskan prinsip untuk arsitektur bisnis, data, aplikasi, dan teknologi berdasarkan TOGAF ADM yang sesuai dengan proses bisnis yang dijalankan Direktorat Metrologi.
B. Architecture vision

Fase architecture vision merupakan tahap awal dalam TOGAF ADM. Pada fase ini mendefinisikan scope dan stakeholder yang terlibat untuk menghasilkan architecture vision. Value chain digambarkan untuk mengidentifikasi aktivitas bisnis utama dan pendukung yang dijalankan untuk memberikan layanan kepada pelanggan.

Aktivitas bisnis yang dilakukan menggambarkan rangkaian proses yang dilakukan untuk memberikan layanan kepada pelanggan. Penelitian dilakukan pada aktivitas bisnis utama yang digambarkan dengan fungsi bisnis, yaitu fungsi bisnis pengawasan dan fungsi bisnis layanan pelanggan. Selain 
itu pada fase ini digambarkan solusi yang akan dibuat secara high level dalam bentuk solution concept diagram.

TABEL I

PRINSIP-PRINSIP ARSITEKTUR

\begin{tabular}{|l|l|}
\hline \multicolumn{1}{|c|}{ Arsitektur } & \multicolumn{1}{|c|}{ Prinspi } \\
\hline \multirow{4}{*}{ Business architecture } & Keberlangsungan bisnis \\
\cline { 2 - 2 } & Kepatuhan hukum \\
\cline { 2 - 2 } & Berorientasi layanan \\
\cline { 2 - 2 } & Peningkatan tertib ukur \\
\hline \multirow{4}{*}{ Data architecture } & Aset data \\
\cline { 2 - 2 } & Sharing data \\
\cline { 2 - 2 } & Akurasi Data \\
\cline { 2 - 2 } & Keamanan data \\
\cline { 2 - 2 } & Data terpercaya \\
\cline { 2 - 2 } & Esay of use \\
\hline \multirow{4}{*}{ Technology architecture } & Integrasi aplikasi \\
\cline { 2 - 2 } & Ketersediaan aplikasi \\
\cline { 2 - 2 } & Hak akses penggunaan \\
\hline & Perubahan sesuai kebutuhan \\
\cline { 2 - 2 } & Keamanan \\
\cline { 2 - 2 } & Interoperability \\
\cline { 2 - 2 } & Kontrol teknis \\
\hline
\end{tabular}

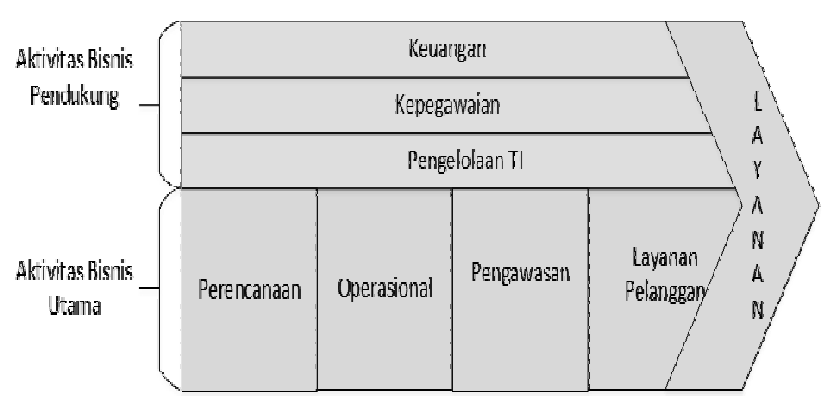

Gambar 2 Value chain diagram

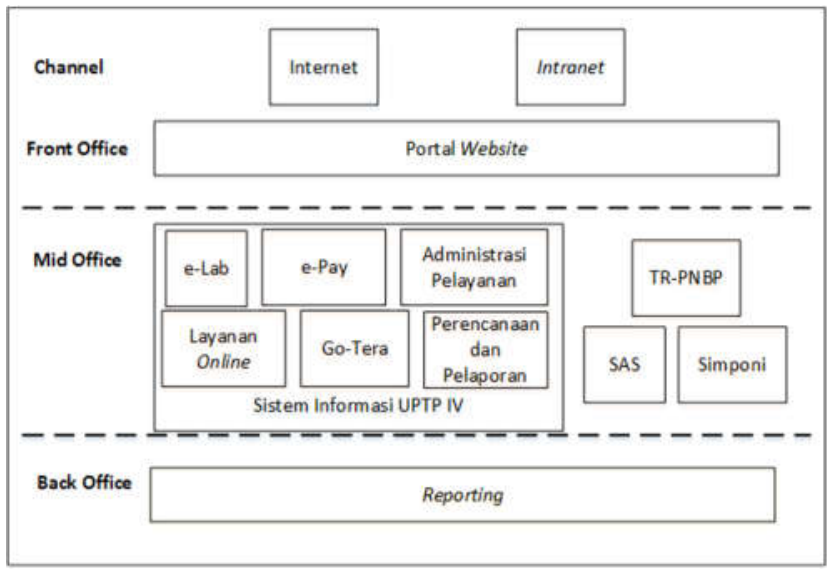

Gambar 3 Solution concept diagram

Solusi sistem dibangun dengan menggunakan channel intranet dan internet untuk mengakses aplikasi. Internet digunakan oleh pengguna yang berada di luar jaringan Direktorat Metrologi, sedangkan intranet digunakan untuk pengguna yang mengakses aplikasi yang tersambung ke jaringan Direktorat Metrologi. Website digunakan sebagai interface saat user mengakses aplikasi. Pada website terdapat aplikasi yang mendukung jalannya proses bisnis. Aplikasi dibuat dengan menggabungkan beberapa aplikasi dalam satu portal website Pada back office terdapat reporting sebagai pengelolaan aplikasi.

\section{Business architecture}

Fase business architecture merupakan fase yang menggambarkan bisnis yang berjalan saat ini dan proses bisnis target yang dikembangkan agar dapat mencapai tujuan perusahaan. Pemodelan proses bisnis merupakan hal yang penting [14]. Terdapat beberapa bahasa dan notasi yang dapat digunakan dalam pemodelan proses bisnis. Namun, BPMN (Business Process Modelling Notation) dan UML (Unified Modelling Language) dianggap sebagai bahasa dan notasi pemodelan proses bisnis yang standar [15]. Driver merupakan pendorong organisasi untuk mencapai goals. Dalam mencapai goals tersebut setiap fungsi bisnis memiliki objective yang harus dicapai.

TABEL II

DRIVERS/GOALS/OBJECTIVE

\begin{tabular}{|c|l|}
\hline \multirow{2}{*}{ Drivers } & $\begin{array}{l}\text { Menciptakan perdagangan dalam negeri yang } \\
\text { tumbuh dan berkualitas }\end{array}$ \\
\hline \multirow{2}{*}{ Goals } & Peningkatan tertib ukur \\
\cline { 2 - 3 } & Peningkatan pelayanan kalibrasi \\
\hline Fungsi Bisnis & \multicolumn{1}{|c|}{ Objective } \\
\hline \multirow{3}{*}{$\begin{array}{c}\text { Layanan } \\
\text { Pelanggan }\end{array}$} & $\begin{array}{l}\text { Meningkatkan jumlah pelanggan yang diberikan } \\
\text { jasa kalibrasi. }\end{array}$ \\
\cline { 2 - 2 } & $\begin{array}{l}\text { Meningkatkan jumlah penilaian mutu pelayanan } \\
\text { kemetrologian }\end{array}$ \\
\hline \multirow{5}{*}{ Pengawasan } & $\begin{array}{l}\text { Meningkatkan pengelolaan mekaisme pelaporan } \\
\text { kinerja Direktorat Metrologi. }\end{array}$ \\
\cline { 2 - 2 } & $\begin{array}{l}\text { Meningkatkan kegiatan pengawasan setiap unit } \\
\text { kerja Direktorat Metrologi }\end{array}$ \\
\hline
\end{tabular}

Kebutuhan bisnis organisasi diidentifikasi berdasarkan driver, goals, dan objective. Requirement dibutuhkan menjadi dasar dalam proses perancangan. Perbandingan antara kondisi existing dan target menghasilkan suatu gap. Gap digunakan sebagai dasar penerapan solusi yang dirancang sebagai upaya meminimalkan gap tersebut agar perusahaan dapat mencapai tujuannya. Tabel III merupakan kebutuhan bisnis pada fungsi bisnis layanan pelanggan dan pengawasan.

TABEL III

REQUIREMENT BISNIS

\begin{tabular}{|c|c|c|}
\hline No & Fungsi Bisnis & Requirement \\
\hline 1. & \multirow{5}{*}{$\begin{array}{l}\text { Layanan } \\
\text { Pelanggan }\end{array}$} & Adanya layanan yang mudah. \\
\hline 2. & & $\begin{array}{l}\text { Adanya layanan terpadu untuk semua } \\
\text { layanan. }\end{array}$ \\
\hline 3. & & $\begin{array}{l}\text { Menyediakan alur layanan yang } \\
\text { terstruktur dan terarah. }\end{array}$ \\
\hline 4. & & Memberikan layanan yang terpercaya. \\
\hline 5 . & & $\begin{array}{l}\text { Memberikan layanan sesuai SOP yang } \\
\text { telah ditentukan. }\end{array}$ \\
\hline 1. & \multirow[t]{2}{*}{ Pengawasan } & $\begin{array}{l}\text { Memiliki sistem pelaporan yang } \\
\text { mudah dan cepat. }\end{array}$ \\
\hline 2. & & Memiliki jadwal kegiatan pelaporan. \\
\hline
\end{tabular}


1. Business service/business process baeline

Tabel IV menjelaskan hubungan antara business service yang dihasilkan dan business process yang saat ini dijalankan oleh fungsi bisnis layanan pelanggan dan pengawasan Direktorat Metrologi. Business process yang dilakukan oleh suatu fungsi bisnis menghasilkan business service.

TABEL IV

BUSINESS SERVICE/BUSINESS PROCESS EXISTING

\begin{tabular}{|c|c|c|}
\hline $\begin{array}{l}\text { Fungsi } \\
\text { Bisnis }\end{array}$ & $\begin{array}{l}\text { Business } \\
\text { Service }\end{array}$ & Business Process \\
\hline \multirow{6}{*}{$\begin{array}{c}\text { Layanan } \\
\text { Pelanggan }\end{array}$} & \multirow{4}{*}{$\begin{array}{l}\text { Penerimaan } \\
\text { permohonan } \\
\text { layanan } \\
\text { kemetrologian }\end{array}$} & $\begin{array}{l}\text { Proses penerimaan } \\
\text { permohonan layanan } \\
\text { pengujian }\end{array}$ \\
\hline & & $\begin{array}{l}\text { Proses penerimaan } \\
\text { permohonan pengujian insitu }\end{array}$ \\
\hline & & $\begin{array}{l}\text { Proses penerimaan } \\
\text { permohonan penerbitan izin } \\
\text { onsite }\end{array}$ \\
\hline & & $\begin{array}{l}\text { Proses penerimaan } \\
\text { permohonan penerbitan izin } \\
\text { online }\end{array}$ \\
\hline & \multirow{2}{*}{$\begin{array}{l}\text { Penyerahan } \\
\text { hasil } \\
\text { pengujian }\end{array}$} & $\begin{array}{l}\text { Proses penyerahan hasil } \\
\text { pengujian/penerbitan izin }\end{array}$ \\
\hline & & Proses penyerahan alat uttp \\
\hline \multirow{2}{*}{ Pengawasan } & $\begin{array}{l}\text { Monitoring } \\
\text { kinerja }\end{array}$ & $\begin{array}{l}\text { Proses penyusunan laporan } \\
\text { bulanan/ triwulan pelayanan } \\
\text { kemetrologian }\end{array}$ \\
\hline & $\begin{array}{l}\text { Pelaporan } \\
\text { kinerja }\end{array}$ & $\begin{array}{l}\text { Proses penyusunan laporan } \\
\text { akuntabilitas kinerja instansi } \\
\text { pemerintah }\end{array}$ \\
\hline
\end{tabular}

2. Business service/business process target

Business process target merupakan perubahan proses bisnis yang ada saat ini ke proses bisnis baru. Perbaikan dilakukan dengan penambahan proses bisnis baru dan perbaikan proses bisnis yang ada. Perbaikan proses bisnis dibuat sesuai prinsip bisnis dan perusaahan serta kebutuhan bisnis. Perbaikan proses bisnis yang ada dilakukan dengan penambahan sistem atau perubahan sistem yang digunakan dalam menjalankan aktivitas pada proses bisnis tersebut. Pada rancangan arsitektur bisnis target aktivitas pelayanan pelanggan dapat dilakukan di loket maupun secara online. Sedangkan pada fungsi bisnis pengawasan terdapat penambahan sistem yang digunakan dalam melakukan kegiatan pelaporan. Selain itu sistem juga digunakan untuk menyimpan arsip laporan dalam bentuk softcopy sehingga memudahkan dalam proses pencarian arsip.

Berikut hubungan antara business service yang dihasilkan dan business process target pada fungsi bisnis layanan pelanggan dan pengawasan Direktorat Metrologi.

\section{Information system architecture}

Information system architecture menjelaskan tentang susunan dan hubungan data dan aplikasi yang dibutuhkan oleh organisasi dalam menjalankan proses bisnisnya. Perancangan data dan aplikasi disusun terkait data dan aplikasi yang dibutuhkan pada fungsi bisnis layanan pelanggan dan pengawasan.
TABEL V

BUSINESS SERVICE/BUSINESS PROCESS TARGET

\begin{tabular}{|c|c|c|}
\hline Fungsi Bisnis & $\begin{array}{l}\text { Business } \\
\text { Service }\end{array}$ & Business Process \\
\hline \multirow{3}{*}{$\begin{array}{l}\text { Layanan } \\
\text { Pelanggan }\end{array}$} & \multirow{3}{*}{$\begin{array}{l}\text { Penerimaan } \\
\text { permohonan } \\
\text { layanan } \\
\text { kemetrologian }\end{array}$} & $\begin{array}{l}\text { Penerimaan Permohonan } \\
\text { Layanan Pengujian Onsite }\end{array}$ \\
\hline & & $\begin{array}{l}\text { Penerimaan Permohonan } \\
\text { Layanan Pengujian Online }\end{array}$ \\
\hline & & $\begin{array}{l}\text { Penerimaan Permohonanan } \\
\text { Layanan Pengujian Insitu } \\
\text { Onsite }\end{array}$ \\
\hline \multirow{7}{*}{$\begin{array}{l}\text { Layanan } \\
\text { Pelanggan }\end{array}$} & & $\begin{array}{l}\text { Penerimaan Permohonan } \\
\text { Layanan Pengujian Insitu } \\
\text { Online }\end{array}$ \\
\hline & & $\begin{array}{l}\text { Penerimaan Permohonan } \\
\text { Layanan Penerbitan Izin Onsite }\end{array}$ \\
\hline & & $\begin{array}{l}\text { Penerimaan Permohonan } \\
\text { Layanan Penerbitan Izin } \\
\text { Online }\end{array}$ \\
\hline & \multirow{4}{*}{$\begin{array}{l}\text { Penyerahan } \\
\text { hasil } \\
\text { pengujian }\end{array}$} & $\begin{array}{l}\text { Proses Penyerahan Hasil } \\
\text { Pengujian/Penerbitan Izin } \\
\text { Onsite }\end{array}$ \\
\hline & & $\begin{array}{l}\text { Prose Penyerahan Hasil } \\
\text { Pengujian/Penerbitan Izin } \\
\text { Online }\end{array}$ \\
\hline & & $\begin{array}{l}\text { Proses Penyerahan Alat UTTP } \\
\text { Onsite }\end{array}$ \\
\hline & & $\begin{array}{l}\text { Proses Penyerahan Alat UTTP } \\
\text { Online }\end{array}$ \\
\hline \multirow{2}{*}{ Pengawasan } & $\begin{array}{l}\text { Monitoring } \\
\text { kinerja }\end{array}$ & $\begin{array}{l}\text { Proses penyusunan laporan } \\
\text { bulanan/ triwulan pelayanan } \\
\text { kemetrologian }\end{array}$ \\
\hline & $\begin{array}{l}\text { Pelaporan } \\
\text { kinerja }\end{array}$ & $\begin{array}{l}\text { Proses penyusunan laporan } \\
\text { akuntabilitas kinerja instansi } \\
\text { pemerintah }\end{array}$ \\
\hline
\end{tabular}

1. Information system architecture baseline

Information system architecture baseline menjelaskan data dan aplikasi yang sata ini digunakan dalam kegiatan proses bisnis pada fungsi layanan pelanggan dan pengawasan. Aplikasi yang digunakan pada layanan pelanggan, yaitu website SPPK dan aplikasi Loket. Website SPPK menangani penerimaan layanan perizinan secara online. Sedangkan aplikasi Loket menangani penerimaan layanan pengujian secara onsite. Data yang terdapat pada aplikasi Loket belum bisa digunakan secara langsung untuk keperluan proses bisnis selanjutnya. Pada fungsi bisnis pengawasan tidak terdapat aplikasi yang mendukung jalannya proses bisnis.

\section{Information system architecture target}

Information system architecture target membahas mengenai hasil rancangan terkait data dan aplikasi yang digunakan untuk menunjang kebutuhan bisnis. Rancangan dihasilkan berdasarkan identifikasi kebutuhan data dan aplikasi pada fungsi bisnis layanan pelanggan dan pengawasan. Identifikasi kebutuhan entitas data dan hubungan antar entitas data dilakukan berdasarkan proses bisnis usulan. Komponen aplikasi diidentifikasi menurut kebutuhan aplikasi yang diperlukan untuk menunjang jalannya proses bisnis usulan. Berikut rancangan apikasi pada fungsi bisnis layanan pelanggan dan pengawasan. 


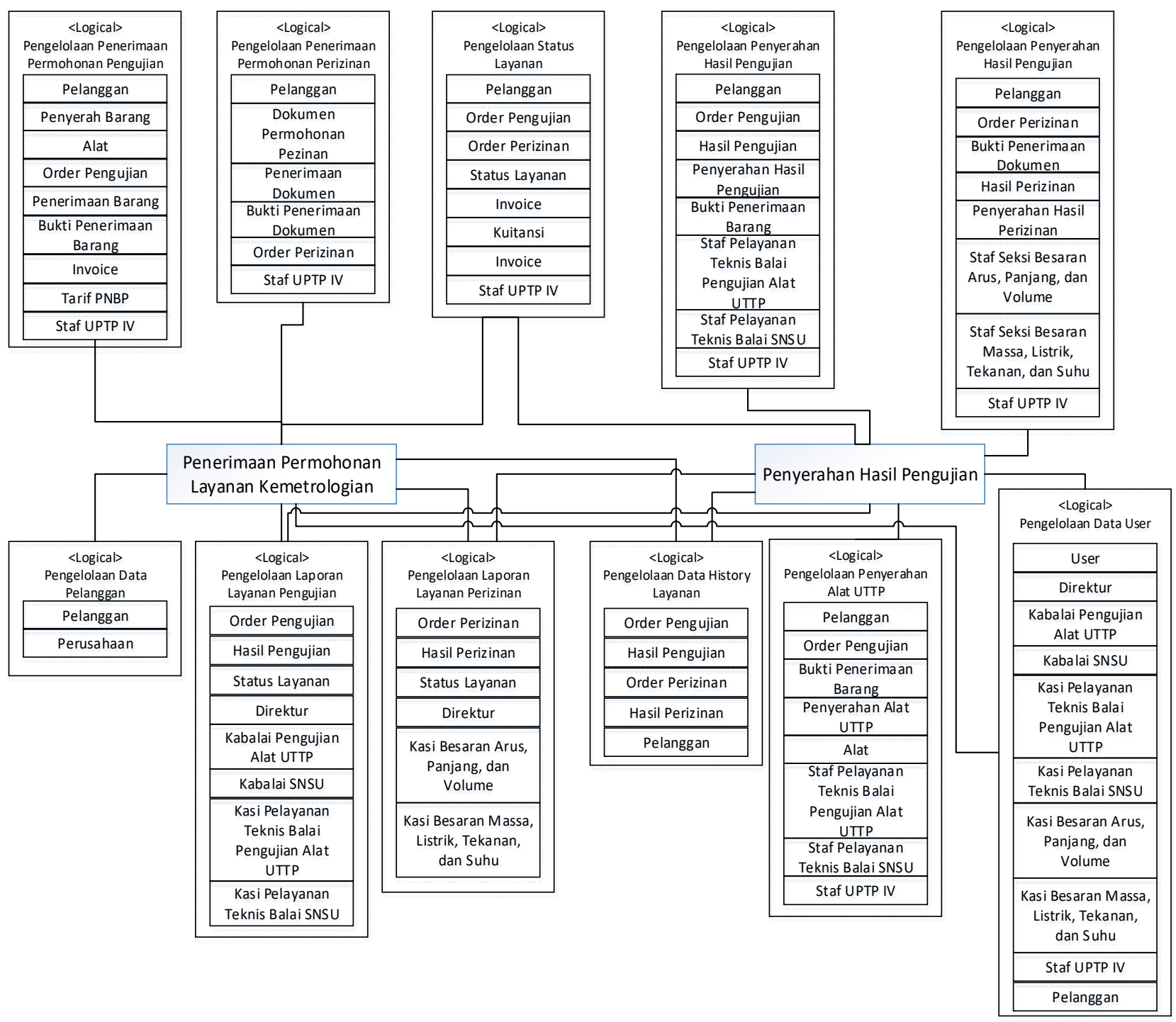

Gambar 4 Data dissemination diagram fungsi bisnis layanan pelanggan 


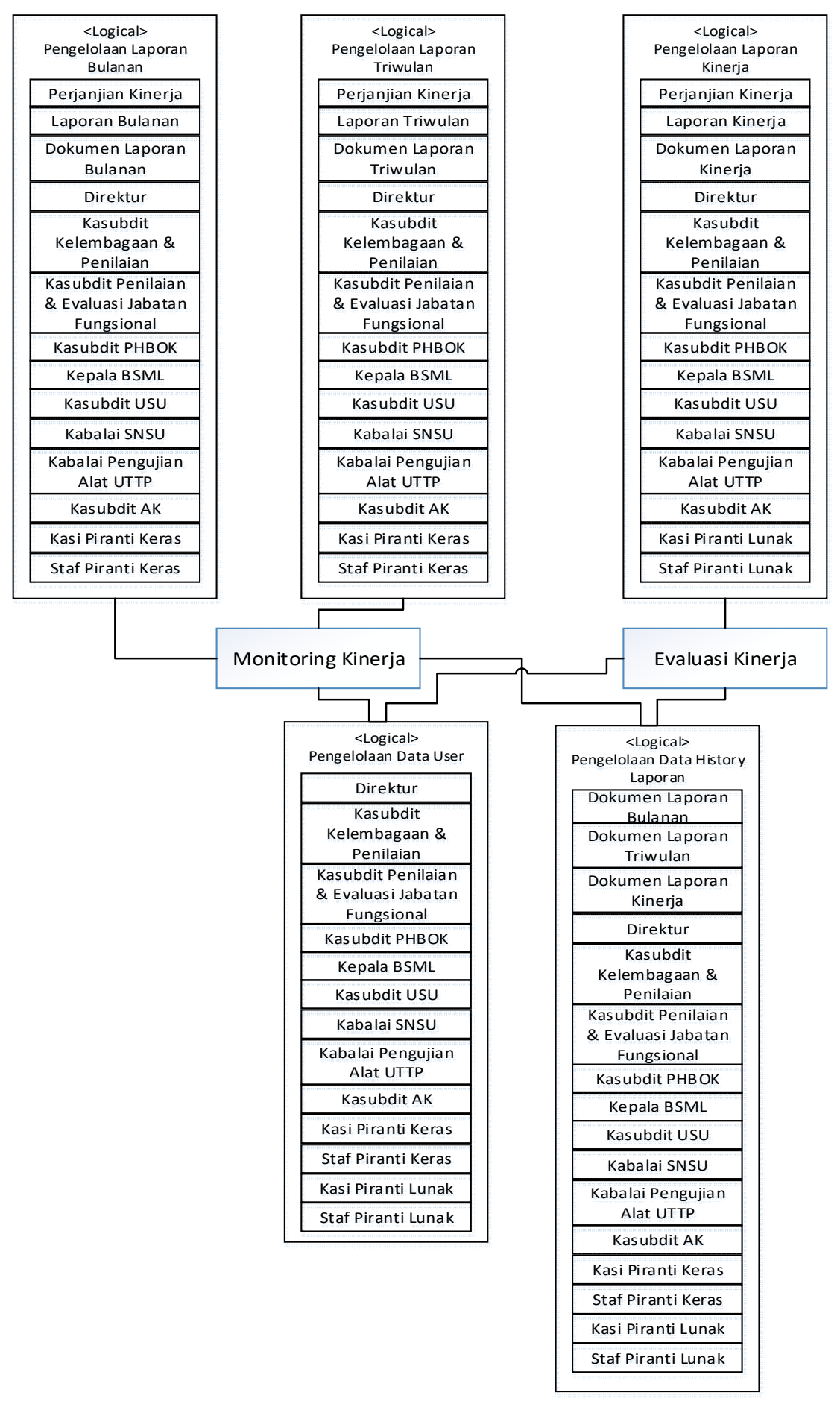

Gambar 5 Data dissemination diagram fungsi pengawasan 
TABEL VI

LOGICAL APPLICATION

\begin{tabular}{|c|l|}
\hline No. & \multicolumn{1}{|c|}{ Logical Application } \\
\hline 1. & Pengelolaan Data Pelanggan \\
\hline 2. & Pengelolaan Penerimaan Permohonan Perizinan \\
\hline 3. & Pengelolaan Penerimaan Permohonan Pengujian \\
\hline 4. & Pengelolaan Status Layanan \\
\hline 5. & Pengelolaan Penyerahan Hasil Pengujian \\
\hline 6. & Pengelolaan Penyerahan Hasil Perizinan \\
\hline 7. & Pengelolaan Penyerahan Alat UTTP \\
\hline 8. & Pengelolaan Data History Layanan \\
\hline 9. & Pengelolaan Laporan Layanan Pengujian \\
\hline 10. & Pengelolaan Laporan Layanan Perizinan \\
\hline 11. & Pengelolan Data User \\
\hline 12. & Pengelolaan Laporan Bulanan \\
\hline 13. & Pengelolaan Laporan Triwulan \\
\hline 14. & Pengelolaan Laporan Kinerja \\
\hline 15. & Pengelolaan Data History Laporan \\
\hline
\end{tabular}

Setiap aplikasi yang ada memiliki entitas data yang berhubungan. Hubungan entitas data, aplikasi dan business service yang didukung oleh aplikasi tersebut digambarkan dalam data dissemination diagram pada Gambar 4 untuk fungsi bisnis layanan pelanggan dan Gambar 5 untuk fungsi bisnis pengawasan. Logical application yang dirancang direkomendasikan untuk digabungkan kedalam beberapa physical application yaitu website UPTP IV, aplikasi Administrasi Layanan, dan aplikasi Pelapor. Penggolongan dilakukan berdasarkan fungsional aplikasi untuk menunjang kebutuhan bisnis yang sama. Tabel VII menjelaskan pengelompokkan logical application.

TABEL VII

REKOMENDASI APLIKASI

\begin{tabular}{|c|c|}
\hline Aplikasi & Logical Application \\
\hline \multirow{6}{*}{$\begin{array}{l}\text { Website } \\
\text { UPTP IV }\end{array}$} & Pengelolaan Data Pelanggan \\
\hline & Pengelolaan Penerimaan Permohonan Perizinan \\
\hline & Pengelolaan Penerimaan Permohonan Pengujian \\
\hline & Pengelolaan Status Layanan \\
\hline & Pengelolaan Data History Layanan \\
\hline & Pengelolan Data User \\
\hline \multirow{11}{*}{$\begin{array}{c}\text { Administrasi } \\
\text { Layanan }\end{array}$} & Pengelolaan Data Pelanggan \\
\hline & Pengelolaan Penerimaan Permohonan Perizinan \\
\hline & Pengelolaan Penerimaan Permohonan Pengujian \\
\hline & Pengelolaan Status Layanan \\
\hline & Pengelolaan Penyerahan Hasil Pengujian \\
\hline & Pengelolaan Penyerahan Hasil Perizinan \\
\hline & Pengelolaan Penyerahan Alat UTTP \\
\hline & Pengelolaan Data History Layanan \\
\hline & Pengelolaan Laporan Layanan Pengujian \\
\hline & Pengelolaan Laporan Layanan Perizinan \\
\hline & Pengelolan Data User \\
\hline \multirow{5}{*}{ Pelapor } & Pengelolan Data User \\
\hline & Pengelolaan Laporan Bulanan \\
\hline & Pengelolaan Laporan Triwulan \\
\hline & Pengelolaan Laporan Kinerja \\
\hline & Pengelolaan Data History Laporan \\
\hline
\end{tabular}

\section{E. Technology architecture}

Technology architecture menjelaskan rancangan arsitektur teknologi yang digunakan sebagai landasan untuk mendukung jalannya sistem informasi yang digunakan guna memenuhi kebutuhan bisnis. Berikut kebutuhan teknologi yang harus dipenuhi agar sistem informasi yang dirancang dapat berjalan dengan baik.

TABEL VIII

\begin{tabular}{|c|l|}
\hline No. & \multicolumn{1}{|c|}{ REQUIREMENT TECHNOLOGY ARCHITECTURE } \\
\hline 1. & Infrastruktur yang sesuai dengan kebutuhan aplikasi \\
\hline 2. & $\begin{array}{l}\text { Infrastruktur yang dapat mendukung komunikasi } \\
\text { antar aplikasi }\end{array}$ \\
\hline 3. & $\begin{array}{l}\text { Adanya pemeliharaan dan monitoring infrastruktur } \\
\text { secara rutin }\end{array}$ \\
\hline 4. & Adanya firewall untuk menjaga keamanan jaringan \\
\hline 5. & Adanya protokol keamanan aplikasi web \\
\hline 6. & $\begin{array}{l}\text { Adanya antivirus untuk menjaga keamanan aplikasi } \\
\text { dan data }\end{array}$ \\
\hline 7. & Adanya data center yang terpusat \\
\hline 8. & Adanya backup data center \\
\hline 9. & Adanya link backup jaringan. \\
\hline 10. & Adanya backup data secara berkala. \\
\hline 11. & $\begin{array}{l}\text { Adanya jaringan yang menghubungkan kantor } \\
\text { BSML dengan kantor Direktorat Metrologi. }\end{array}$ \\
\hline
\end{tabular}

1. Technology architecture baseline

Penggunaan komponen teknologi serta hubungan antar komponen teknologi yang digunakan saat ini dijelaskan dalam diagram pada Gambar 6. Jaringan yang ada di kantor Direktorat Metrologi hanya berasal dari jaringan Kementerian Perdagangan. Jika terdapat gangguan pada jaringan tersebut maka kantor Direktorat Metrologi tidak dapat mengakses ke jaringan internal Kementerian maupun ke internet. Hal ini menghambat dalam proses pelayanan pelanggan karena karyawan tidak dapat mengakses aplikasi sehingga pelayanan dilakukan secara manual. Selain itu tidak terdapat backup server sebagai cadangan apabila server aplikasi mengalami gangguan.

Keamanan yang ada pada arsitektur teknologi saat ini termasuk sangat minim karena tidak terdapat firewall yang digunakan sebagai upaya dalam mengamankan jaringan. Antivirus yang terdapat pada setiap server tidak terpusat dan tidak terdapat jadwal update antivitus secara berkala. Hal tersebut menunjukkan bahwa terdapat kerentanan yang cukup tinggi pada arsitektur teknologi saat ini sehingga diperlukan perbaikan.

\section{Technology architecture target}

Arsitektur teknologi target dirancang untuk mendukung jalannnya rancangan arsitektur sistem informasi yang telah dibuat untuk memenuhi kebutuhan arsitektur bisnis. Pada arsitektur teknologi target terdapat penambahan beberapa komponen teknologi yang digunakan. Rancangan technology architecture dibuat berdasarkan requirement arsitektur teknologi yang telah didefinifikan. Gambar 7 menggambarkan rancangan technology architecture target.

Penambahan komponen teknologi tersebut berupa penambahan firewall sebagai keamanan jaringan untuk mencegah user yang tidak berwenang masuk ke dalam jaringan internal Direktorat Metrologi. Antivirus digunakan untuk mengamankan aplikasi yang digunakan dan data yang tersimpan pada server. Antivirus dibuat secara terpusat dengan penambahan berupa server antivirus yang menyediakan antivirus kepada seluruh server. 


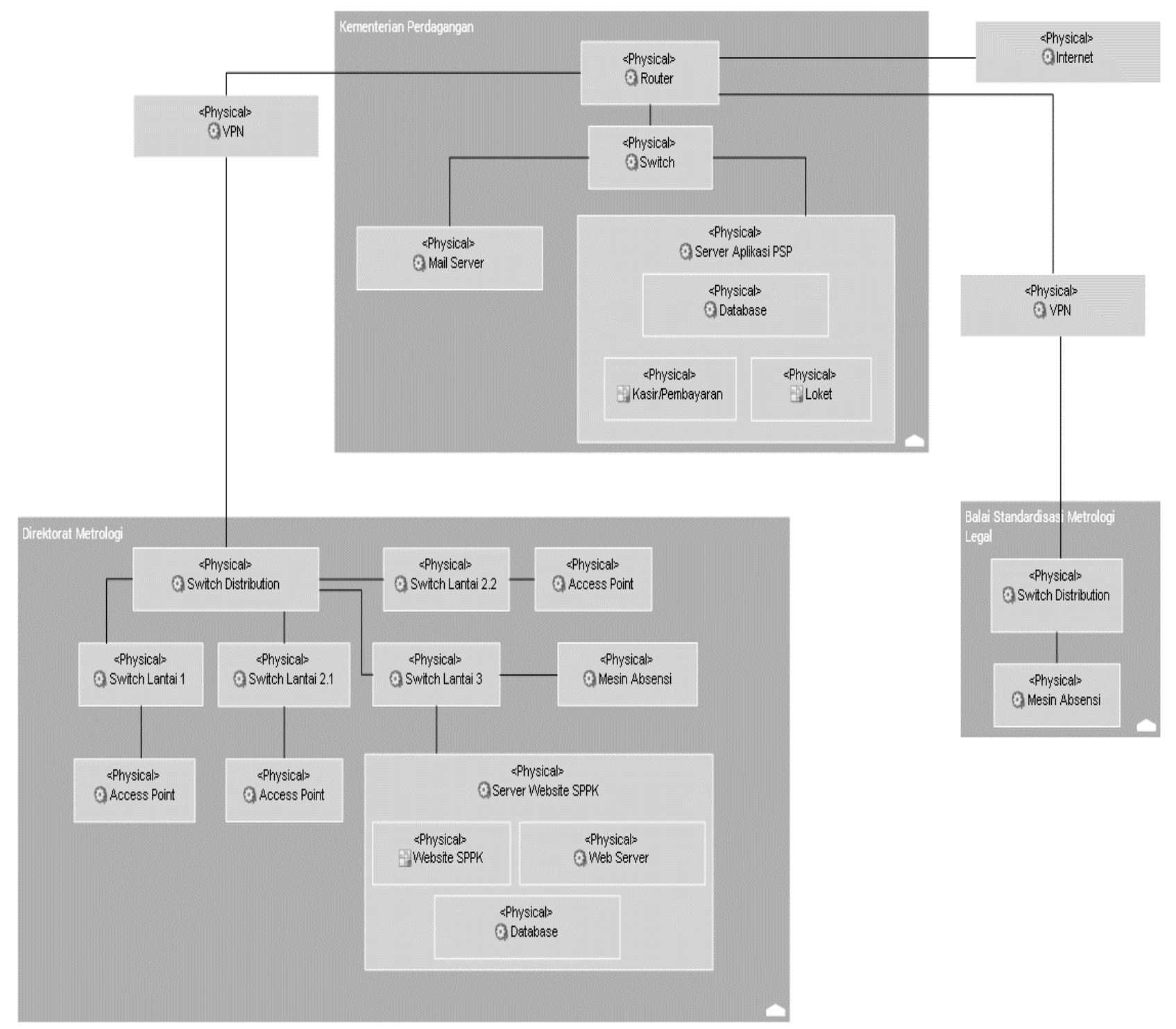

Gambar 6 Environment and location diagram baseline

Network monitoring system ditambahkan untuk memantau aktivitas yang ada pada jaringan maupun server. $\log$ yang dihasilkan pada network monitoring system dapat dianalisis dan diketahui ancaman atau serangan apa yang mungkin didapatkan pada jaringan Direktorat Metrologi. Selain itu terdapat penambahan link backup yang berasal dari ISP sebagai antisipasi jika terdapat gangguan pada jaringan VPN dari Kementerian Perdagangan. Hal ini dilakukan agar tidak terdapat kendala pelayanan pelanggan apabila terdapat gangguan jaringan.

Terdapat perubahan fungsi server yang ada pada teknologi komponen existing. Server yang tersimpan pada kantor Kementerian Perdagangan fungsinya berubah menjadi server backup untuk aplikasi yang digunakan oleh Direktorat Metrologi. Server utama aplikasi Direktorat Metrologi Disimpan di Kantor Pusat Direktorat Metrologi. Hal ini bertujuan untuk memudahkan pihak Direktorat Metrologi dalam mengelola aplikasi yang digunakan sendiri.

\section{F. Validasi}

Validasi dilakukan untuk mengetahui antara rancangan yang dibuat dengan kebutuhan Direktorat Metrologi, khususnya pada fungsi bisnis layanan pelanggan dan pengawasan. Validasi dilakukan dengan meminta feedback dalam bentuk kuisioner yang diisi oleh pihak Direktorat Metrologi. Kuisioner dibuat dengan memberikan rentang poin penilaian 1-5 untuk masing-masing poin pada kuisioner.

Berdasarkan keseluruhan poin penilai yang diperoleh dari hasil kuisioner diperoleh rata-rata poin nilai untuk keseluruhan arsitektur yaitu 4,25. Hal ini menunjukkan bahwa keseluruhan rancangan enterprise architecture telah sesuai dan memenuhi kebutuhan bisnis, data, aplikasi dan teknologi Direktorat Metrologi. Rancangan arsitektur teknologi memiliki rata-rata poin penilaian 4,7. Poin tersebut merupakan poin tertinggi dibandingkan rata-rata poin penilaian pada arsitekur bisnis, data, dan aplikasi. Perolehan poin penilaian tertinggi 
tersebut menunjukkan bahwa arsitektur teknologi yang dirancang paling bagus, sesuai dengan kebutuhan Direktorat Metrologi.

\section{KESIMPULAN}

Rancangan enterprise architecture yang dihasilkan digunakan sebagai pedoman dalam pengembangan TI Direktorat Metrologi. Rancangan dibuat dengan memperhatikan kebutuhan bisnis, sistem informasi, dan teknologi Direktorat Metrologi untuk dapat mencapai tujuan organisasi. Rancangan enterprise architecture meliputi rancangan arsitektur bisnis, arsitektur sistem informasi, dan arsitektur teknologi. Pada arsitektur bisnis dilakukan pengembangan dengan penambahan sistem yang digunakan saat menjalankan aktivitas pada proses bisnis dan penambahan proses bisnis baru. Berdasarkan hasil rancangan layanan pelanggan nantinya dapat dilakukan di loket maupun secara online. Sedangkan untuk proses pelaporan ditambahkan sistem sehingga proses yang dijalankan lebih terstruktur. Pada arsitektur sistem informasi terdapat penambahan entitas data dan penambahan komponen aplikasi serta integrasinya. Pada rancangan arsitektur teknologi terdapat penambahan komponen teknologi yang digunakan untuk menunjang jalannya arsitektur sistem informasi yang telah dirancang.

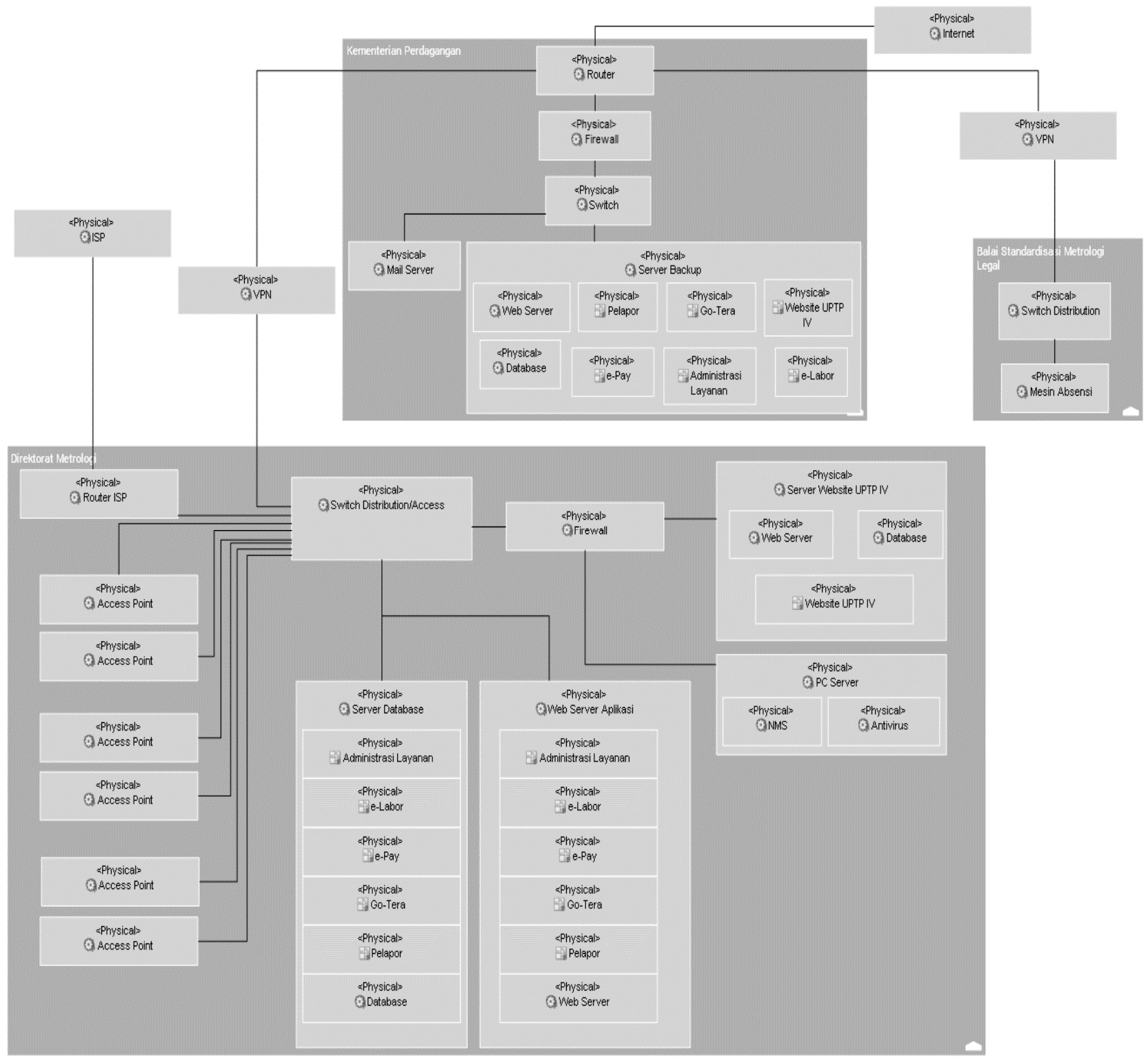

Gambar 7 Environment and location diagram target

DAFTAR PUSTAKA

[1] Yunis, R., \& Surendro, K., Perancangan Model Enteprise Architecture Dengan TOGAF Architecture Development 
Method, Seminar Nasional Aplikasi Teknologi Informasi, 2009

[2] Tamm,T., Seddon, Peter B., Shanks, G., and Reynolds, P., How Does Enterprise Architecture Add Value to Organisations?, Communication of AIS, Vol. 20, No. 01, 2011

[3] Proper, E., \& Greefhorst, Danny, Principle in an Enterprise Architecture Context, Journal of Enterprise Architecture, vol. 7, no.01, 2011

[4] Manolita, R., Murahartawaty, M., \& Hanafi, R. (2016). Perancangan Business Architecture untuk Fungsi Akademik Pada Institut XYZ Menggunakan Framework TOGAF ADM Studi Kasus Sistem Informasi Akademik (SIAKAD). Jurnal Rekayasa Sistem \& Industri (JRSI), 3(01), 33-39.

[5] Zulaiha, Siti., Perancangan Enterprise Architecture Menggunakan TOGAF Di Direktorat Jenderal Perbendaharaan Departemen Keuangan, Tesis Program Magister Teknik Elektro Institut Teknologi Bandung, Bandung, 2009

[6] Affandi, Adityo., Perancangan Arsitektur Enterprise Sistem Informasi Pelayanan Pelanggan PDAM Kota Cirebon, Tesis Program Magister Sistem Informasi Unversitas Komputer Indonesia, Bandung, 2014

[7] Ghozali, Imam dan Handayaningsih, Sri, Pembuatan Model Customer Relationship Management (CRM) E-Government Di Dinas Kelautan dan Perikanan DIY, Jurnal Sarjana Teknik Informatika Universitas Ahmad Dahlan. Vol. 2 No. 1, pp. 780789,2014

[8] Mardiansyah, C. R., Analisis dan Pengembangan Enterprise Architecture Menggunakan Framework TOGAF Pada Pengadilan Agama Bandung, Tugas Akhir Sistem Informasi Universitas Widyatama, Bandung, 2012

[9] Rouhani, B. D., Mahrin, M. N., Nikpay, F., \& Nikfard, P. (2013). A Comparison Enterprise Architecture Implementation Methodologies. International Conference on Informatics and Creative Multimedia (p. 16). IEEE.

[10] Niemi, E., \& Pekkola, S., Enterprise Architecture Quality Aributes: A Case Study, 46th Hawaii International Conference on System Sience, IEEE Computer Society, Hawai, 2013, pp. 3878-3887

[11] Setiawan, Erwin B., Pemilihan EA Framework, Seminar Nasional Aplikasi Teknologi Informasi, 2009

[12] http://pubs.opengroup.org/architecture/togaf9-doc/arch/, diakses Mei 2017

[13] Robinson, S., Conceptual Modelling For Simulation. the 2013 Winter Simulation Conference (pp. 377-388). Loughborough: IEEE, 2013

[14] Saven, R. S. (2003). Business Process Modelling: Review and Framework. Elevier, 130-149

[15] Rodriguez, A., Medina, E. F., \& Platini, M. (2007). A $B P M N$ Extension for the Modeling of Security Requirenments in Business Process. IEICE Trans, 745751. 